\title{
Endoscopic Transnasal Surgery as a Replacement for Maxillotomy Techniques to Approach the Central Skull Base: Fewer Complications and More Acceptable to Patients?
}

\author{
David Choi ${ }^{1} \quad$ Ashok Subramanian $^{1} \quad$ Vivian Elwell ${ }^{1}$ \\ ${ }^{1}$ Department of Neurosurgery, The National Hospital for Neurology \\ and Neurosurgery, London, United Kingdom \\ 2 Department of ENT, The Royal National Throat Nose Ear Hospital, \\ London, United Kingdom \\ ${ }^{3}$ Department of ENT, Guy's and St Thomas' Hospital NHS Trust, \\ London, United Kingdom
}

\author{
Peter Andrews ${ }^{2}$ David Roberts ${ }^{3}$ Michael Gleeson ${ }^{1,3}$
}

J Neurol Surg B 2014;75:165-170.

\begin{abstract}
Address for correspondence David Choi, FRCS, PhD, Department of Neurosurgery, The National Hospital for Neurology and Neurosurgery, Queen Square, London WC1N 3BG, United Kingdom (e-mail: David.choi@uclh.nhs.uk).
\end{abstract}

\begin{abstract}
Objectives To compare the complication rates of endoscopic transnasal and open maxillotomy approaches for the central skull base.

Design Retrospective review.

Setting Single-center study, London, United Kingdom.

Participants From 1992 to 2012, 81 patients underwent surgery for skull base lesions, 59 by maxillotomy and 22 by endoscopy.

Main Outcome Measures Total time of surgical anesthesia, blood loss, complications, duration of tracheal intubation, duration of hospital stay, myelopathy score, and mortality rate.

Results The surgical time, blood loss, and duration of the postoperative intubation period were significantly less with endoscopy $(p<0.001)$. Requirements for intensive

Keywords

- maxillotomy

- endoscopy

- skull base

- surgery

- complications care, ward stay, and total hospital stay were also significantly less in the endoscopic group ( $p=0.01, p<0.001$, and $p<0.001$, respectively). The complication rate was lower with transnasal endoscopic surgery.

Conclusion In patients for whom open maxillotomy or endoscopic surgery are both feasible, the preference should be to perform endoscopic surgery, with better visualization and fewer complications.
\end{abstract}

\section{Introduction}

Surgery for ventral midline skull base pathologies is challenging due to the central location and surrounding structures that make access difficult. Open surgical approaches include extended lateral, posterolateral, anterior subfrontal, transglabellar, and pterional or lateral transtemporal routes. ${ }^{1-6}$ However, purely midline pathology is best approached via the midline, and for this purpose the standard transoral operation was developed to include a maxillotomy, ${ }^{7-11}$ thereby allowing more superior exposure as far as the pituitary fossa (-Fig. $\mathbf{1}$ ).

This so-called open-door maxillotomy became the mainstay of surgery for clivus chordomas and basilar impression from rheumatoid disease and congenital syndromes ${ }^{9,10,12}$ and was a very effective technique that avoided transgressing the planes of cranial nerves and arteries. A modified received

June 8, 2013

accepted

August 19, 2013

published online

March 12, 2014 (c) 2014 Georg Thieme Verlag KG Stuttgart · New York
DOI http://dx.doi.org/ 10.1055/s-0033-1358375. ISSN 2193-6331. 


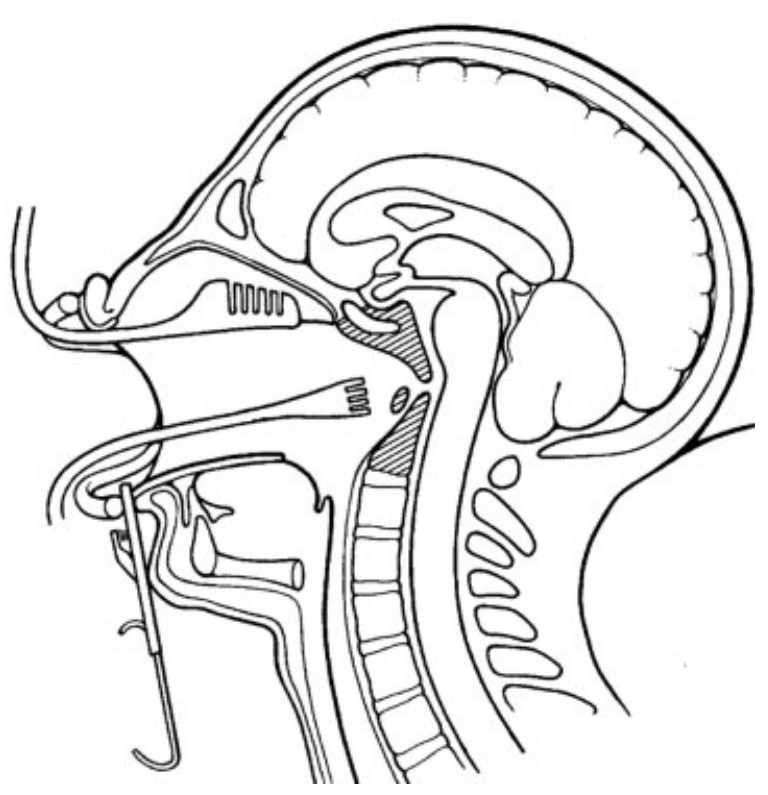

Fig. 1 Schematic diagram of the possible surgical exposure via an open-door maxillotomy.

transfacial approach provides similar access but requires rotation of the nose on a pedicle flap. ${ }^{4}$ These approaches are technically demanding and require experience in maxillofacial techniques, and they can be rather time consuming.

Over the past decade, endoscopic techniques for sinus surgery have developed to include approaches to the anterior skull base and intracranial compartments. ${ }^{13-18}$ Endoscopic surgery is potentially quicker and more acceptable to patients. Although short-term results are encouraging, the longterm results are awaited.

The endoscopic transnasal approach has a steep learning curve and increased risk of cerebrospinal fluid (CSF) leakage, but advances in the technique and a team approach between neurosurgeons and otolaryngologists have decreased the potential risks. ${ }^{18}$ Major advantages of the endoscopic approach are better visualization of structures and a direct approach without the need for brain retraction.

This study compared the complication rates of the endoscopic transnasal approach and maxillotomy techniques performed in a single center. In the past decade, there has been a step change from maxillotomy techniques to the use of endoscopic transnasal surgery, and we present our early experience.

\section{Material and Methods}

A retrospective review of medical records of consecutive patients who underwent surgery for skull base lesions in our institution was performed including surgery by endoscopic transnasal approach or maxillotomy techniques between 1992 and 2012. Demographic and clinical information was studied including the diagnosis, preoperative tumor volume, surgical approach, surgical time, intraoperative blood loss, complications, duration of postoperative intu- bated days, length of postoperative stay in the intensive care unit (ICU) and total hospital stay, need for supplemental feeding by nasogastric or percutaneous endoscopic gastrostomy (PEG), whether craniocervical junction fixation was performed, pre- and postoperative Ranawat myelopathy score, and mortality rate. Patients were regularly followed in the outpatient clinic at serial intervals, and the need for further surgical procedures either due to a complication or due to progression of the disease was documented.

The Student $t$ test was used to identify the statistical differences in parameters and outcomes. Complication rates were compared using the chi-square test. The $p$ values $<0.05$ were considered statistically significant.

\section{Surgical Technique}

\section{Open-Door Maxillotomy}

This technique was described previously, ${ }^{19}$ but in brief, an incision is made above the superior gingival line. The face is degloved superiorly as far as the infraorbital neurovascular bundle and external nares, and a Le Fort I osteotomy is performed. The maxilla is then divided in the midline with an oscillating sagittal saw, and the resultant halves of the maxilla are swung laterally to provide midline exposure of the posterior nasopharynx (-Fig. 2).

The pharyngeal mucosa is divided either by an inverted U-shaped flap, or a vertical midline incision. The longus colli and longus capitis muscles are divided in the midline and retracted using custom-made self-retaining retractors (Crockard instruments, Codman). The skull base may be exposed from the sphenoid sinus above, to the $\mathrm{C} 2$ vertebral body below.

\section{Endoscopic Transnasal Surgery}

For technical details, see Stippler et al and Kassam et al. ${ }^{18,20,21}$ Patients were deemed suitable for treatment depending on the anatomy and nature of the surgical target, surgical goals, and review of magnetic resonance imaging (MRI) and computed tomography imaging of lesions, in particular, the position of the hard palate and the degree of lateral extension of the pathology. Neuronavigation (Stealth, Medtronic) was used in most cases. We used a standard zero-degree rigid endoscope and a bimanual binasal technique to approach the sphenoid sinus and clivus. This necessitates opening the posterior nasal septum to allow for a "four-instrument" technique, and lateralization of the middle turbinates. Unlike Kassam et $\mathrm{al}^{20}{ }^{20}$ we do not routinely remove the middle turbinate but outfracture them, displacing the turbinates laterally. For greater exposure, a medial maxillary sinus fenestration may be performed to allow more space for lateralization of the middle turbinate.

\section{Results}

A total of 81 patients underwent surgery for skull base lesions by maxillotomy or endoscopic techniques. In those who underwent maxillotomy, 59 patients underwent a total of 65 procedures. The male-to-female ratio was $28: 31$. A total of 


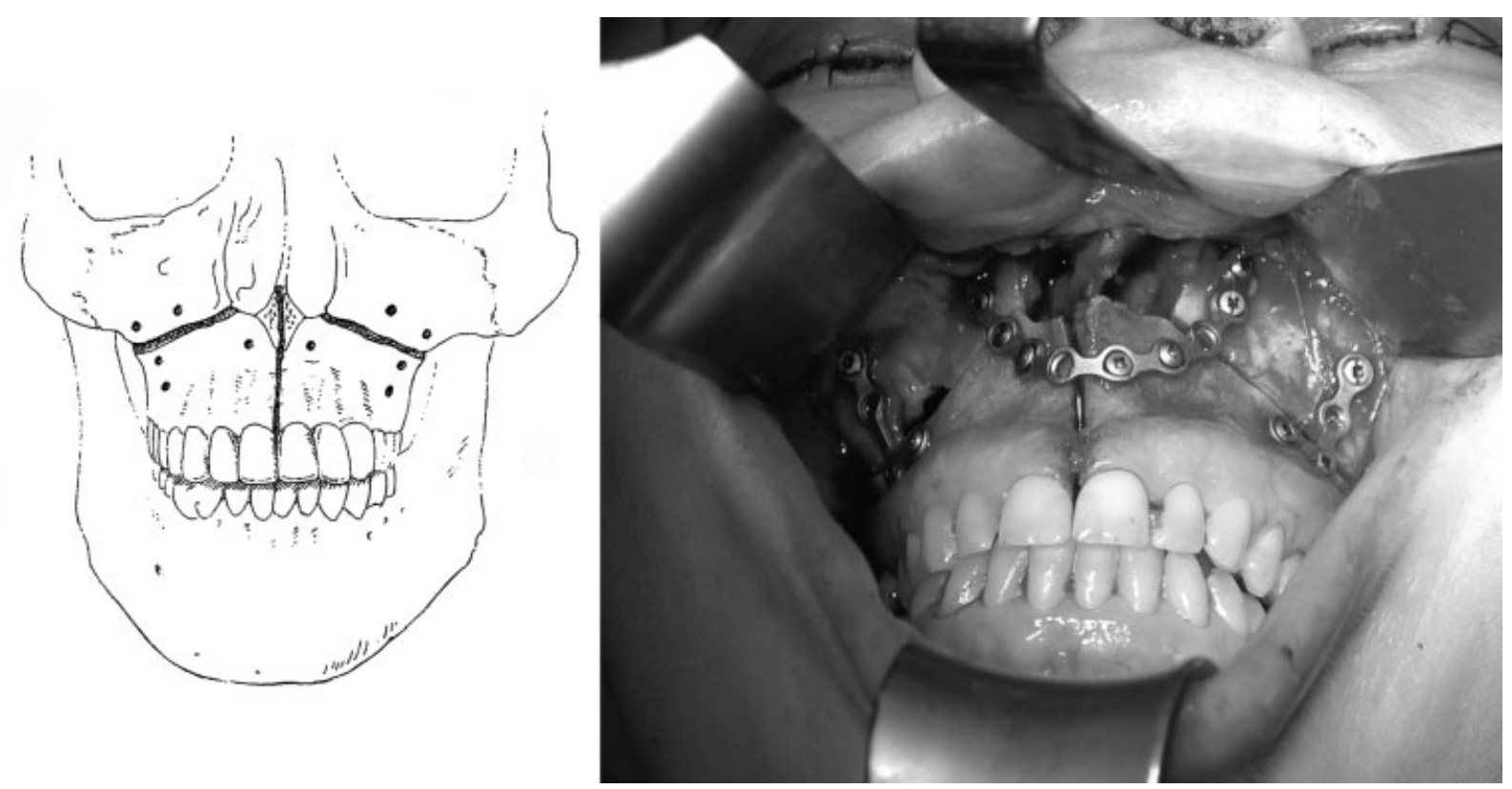

Fig. 2 Diagram of saw cuts for an open-door maxillotomy, and illustration of plates in situ after reconstruction of the maxilla.

58 open-door maxillotomies, 6 midface degloving approaches, and 1 Le Fort type 1 osteotomy were performed. The mean age at operation was 39 years old (standard deviation [SD]: 16). Diagnoses are specified in -Table 1.

Preoperative tumor volumes were estimated from the MRI scans, calculated using the formula " $\mathrm{A} \times \mathrm{B} \times \mathrm{C} / 2$ " where $\mathrm{A}$, $\mathrm{B}$, and $\mathrm{C}$ were the maximum dimensions of the tumor measured on the scans, divided by 2, to estimate volume of a sphere. In the endoscopic surgery group, the mean tumor volume was $53.6 \mathrm{cc}$, standard error was $4.3 \mathrm{cc}$. In the maxillotomy group, mean was $56.6 \mathrm{cc}$, standard error was $5.1 \mathrm{cc}$. There was no significant difference in the tumor volume before surgery in the endoscopic and maxillotomy groups $(p=0.65)$.

A total of 23 operations involved simultaneous occipitocervical fixation to stabilize the craniocervical junction. The mean anesthetic time, from induction to recovery, was 338 minutes (SD: 163 minutes), and mean blood loss was $1695 \mathrm{~mL}$ (SD: $1923 \mathrm{~mL}$ ). Patients were intubated by tracheostomy for a

Table 1 Diagnoses of patients undergoing surgery for maxillotomy and endoscopic groups

\begin{tabular}{|l|l|l|}
\hline Diagnosis & Maxillotomy & Endoscopy \\
\hline Chordoma & 32 & 11 \\
\hline Other malignant tumor & 3 & 3 \\
\hline Benign tumor & 3 & 4 \\
\hline $\begin{array}{l}\text { Congenital basilar } \\
\text { impression }\end{array}$ & 20 & 4 \\
\hline $\begin{array}{l}\text { Rheumatoid basilar } \\
\text { invagination }\end{array}$ & 1 & 0 \\
\hline Infection/other & 6 & 4 \\
\hline
\end{tabular}

mean period of 20 days after surgery (SD: 39 days). Average length of stay in the ICU was 8 days (SD: 19 days), on the ward was 29 days (SD: 38 days), and total hospital stay was 44 days (SD: 76 days). Patients undergoing maxillotomy required nasogastric or PEG feeding for a mean of 24 days (SD: 41 days). - Table 2 summarizes the differences between maxillotomy and endoscopy.

Neurologic function (Ranawat myelopathy grade) remained the same following surgery in 56 procedures, was improved after 4 procedures, and deteriorated after 5 procedures. However, a greater percentage of patients undergoing maxillotomy were myelopathic (30.5\%) compared with the endoscopy group (11.1\%) before surgery. A total of 29 of the 65 procedures had at least one complication with a complication rate of $44.6 \%$ ( - Table 3 ). There were six deaths within 30 days from surgery.

In the endoscopic group, there were 22 patients, including 13 men and 9 women, and a total of 26 procedures. Their mean age at operation was 41 years (SD: 18 years). Diagnoses are shown in - Table 1. Two patients required simultaneous occipitocervical fixation. The mean anesthetic time was 173 minutes (SD: 109 minutes), and the mean blood loss was $438 \mathrm{~mL}$ (SD: $200 \mathrm{~mL}$ ). Patients were intubated postoperatively for a mean of 1 day (SD: 1 day). Intubation $<24$ hours was recorded as 1 day's duration. Average length of stay in ICU after surgery was 1 day (SD: 2 days), ward stay was 8 days (SD: 6 days), and total hospital stay was 9 days (SD: 8 days). Nasogastric feeding was not required in any patient. The neurologic function according to Ranawat grading remained unchanged after all endoscopic procedures. There were complications in 3 of the 26 procedures ( - Table 3 ). There were no deaths within 30 days of surgery. Mean follow-up was 18 months (SD: 16 months). 
Table 2 Comparison of maxillotomy and endoscopic surgeries

\begin{tabular}{|l|l|l|l|}
\hline & Maxillotomy (65 procedures) & Endoscopy (26 procedures) & Significance \\
\hline Mean age, y (SE) & $39(1.9)$ & $41(3.5)$ & $p=0.68$ \\
\hline Anesthetic time, min (SE) & $338(20.2)$ & $173(21.4)$ & $p<0.001$ \\
\hline Blood loss, mL (SE) & $1695(238.5)$ & $438(39.2)$ & $p<0.001$ \\
\hline Intubation, days (SE) & $20(4.8)$ & $1(0.2)$ & $1(0.4)$ \\
\hline Intensive care unit stay, d (SE) & $8(2.4)$ & $8(1.2)$ & $p=0.001$ \\
\hline Ward stay, d (SE) & $29(4.7)$ & 0 & $p<0.001$ \\
\hline Supplementary feeding, d (SE) & $24(5.1)$ & $p<0.001$ \\
\hline
\end{tabular}

Abbreviation: SE, standard error.

Comparison between the maxillotomy and endoscopy groups demonstrated similar ages and durations of preoperative symptoms $(p=0.6, p=1$, respectively). The intraoperative surgical time, blood loss, and duration of postoperative intubation period was significantly less with endoscopy ( $p<0.001, p<0.001$, and $p<0.001$, respectively). Duration of ICU stay, ward stay, and total hospital stay were also significantly less in the endoscopic group $(p=0.01$, $p<0.001$, and $p<0.001$, respectively). The morbidity rate and the mortality rate were significantly lower after transnasal endoscopic surgery (-Fig. 3 ).

In the maxillotomy group, patients had longer follow-up compared with the more recent endoscopic series (mean follow-up of 128 months for maxillotomy and 18 months for endoscopic surgeries; $p<0.001$ ).

Table 3 Number and type of complications after maxillotomy and endoscopic surgeries

\begin{tabular}{|l|l|l|}
\hline Complication & $\begin{array}{l}\text { Open-door } \\
\text { maxillotomy (65) }\end{array}$ & $\begin{array}{l}\text { Endoscopic } \\
\text { transnasal (26) }\end{array}$ \\
\hline $\begin{array}{l}\text { Cerebrospinal } \\
\text { fluid leak }\end{array}$ & 3 & 2 \\
\hline Cardiovascular & 2 & 0 \\
\hline Respiratory & 18 & 0 \\
\hline Dysphagia & 2 & 0 \\
\hline Hematoma & 0 & 0 \\
\hline $\begin{array}{l}\text { Pharyngeal } \\
\text { wound infection }\end{array}$ & 2 & 0 \\
\hline Sepsis & 2 & 0 \\
\hline Meningitis & 6 & 0 \\
\hline $\begin{array}{l}\text { Velopharyngeal } \\
\text { incompetence }\end{array}$ & 13 & 0 \\
\hline Cranial nerve palsy & 2 & 0 \\
\hline Cerebral infarction & 0 & 1 \\
\hline $\begin{array}{l}\text { Internal carotid } \\
\text { artery injury }\end{array}$ & 0 & 1 \\
\hline Death & 6 & 0 \\
\hline
\end{tabular}

Hemorrhage and CSF leakage are potential problems with the endoscopic approach. ${ }^{21-25}$ In our series, there was one internal carotid artery injury and two CSF leaks. In comparison, there were a total of three CSF leaks in the open-door maxillotomy group, although these procedures were generally for more extensive tumor operations.

\section{Discussion}

Lesions in and around the clivus are traditionally approached through open anterior or lateral approaches. ${ }^{1-6}$ Arguably the most direct of these approaches is through the midline by a maxillotomy, facial split technique, or extended transoral route. $^{7-10}$ However, these approaches are technically demanding and less acceptable to patients, and endoscopic transnasal surgery has recently become more popular, partly due to the trend and demand for minimally invasive surgery. Otolaryngologists initially performed endoscopic nasal surgery to treat sinus pathology ${ }^{15,26,27}$ and later expanded the indications in collaboration with neurosurgeons, gaining a better understanding of the anatomy of the skull base and intracranial compartment. The endoscopic approach can also

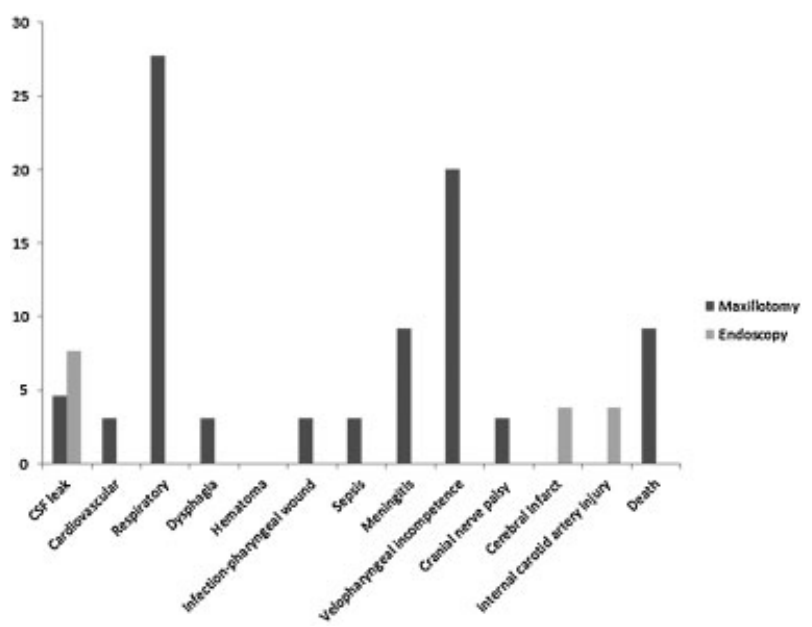

Fig. 3 Graph of percentage complications after maxillotomy and endoscopic surgeries. CSF, cerebrospinal fluid. 
be used to treat lesions of the craniocervical junction. ${ }^{20}$ We present our early results of patients treated by endoscopic surgery, compared with an earlier series of patients who underwent open maxillotomy at our hospital.

In our series, open maxillotomies were associated with a higher incidence of infection, meningitis, systemic sepsis, and respiratory complications, although this is an uncontrolled study, and the patients undergoing maxillotomy had greater comorbidity and worse grades of myelopathy before surgery, and different types and severity of pathology. A total of $28 \%$ of patients treated by the open approach experienced respiratory complication, $9 \%$ had meningitis, and $1.3 \%$ had systemic sepsis. In the endoscopic approach, these risks were far lower. In $20 \%$ of maxillotomy patients, velopharyngeal incompetence was noted with the open approach.

Endoscopic surgery has a steep learning curve. Snyderman et al analyzed their experience of endoscopic surgery for skull base pathology and proposed a training program for acquisition of these surgical skills. ${ }^{28}$ In particular, CSF leakage can be a problem to repair with endoscopic surgery due to the limited view and space available. We demonstrate a 7.7\% CSF leak rate in the endoscopic group as opposed to $4.6 \%$ in the open surgical group. A higher incidence of CSF leak rates after endoscopic surgery is well recognized, occurring in up to $31.6 \%$ of patients. ${ }^{29-32}$ There was no vascular injury in the open group but one case of internal carotid artery injury in the endoscopic group.

Our results are comparable with other published reports. Neurologic morbidity rates for endoscopic skull base surgery ranges from 0 to $80 \%$, vascular injuries are reported in 9 to $12 \%$, and CSF leaks are reported in 8.3 to $30 \%$ of cases. $18,22,24,33$

Patients undergoing open maxillotomies have generally more advanced diseases than patients undergoing standard transoral surgery. The complication rate for standard transoral surgery is much lower, with a CSF leak rate of $1.3 \%$ and pharyngeal infection rate of $0.6 \%$ in our series. ${ }^{34}$ Like Carrabba et al, we found that retrospectively comparing endoscopic and open surgeries was subject to selection bias, perhaps with more complex patients undergoing open surgeries. ${ }^{29}$ However, preoperative tumor volumes were not significantly different between the two groups. The maxillotomy cohort generally underwent operations in the earlier years of this study, and obtaining routine postoperative MRI was not standard procedure at the time. Therefore, it was not possible to compare postoperative tumor volume and extent of resection between the maxillotomy and endoscopy groups. However, the philosophy of surgery in both groups was the same, namely to perform complete or near-complete excision wherever possible. Also, another potential bias is the heterogeneous types of pathologies presenting in the two groups. This being said, most other studies confirm a higher risk of complications in open surgery compared with endoscopic surgery. Casler et al found a greater risk of complications in the open group (53.3\%) compared with the endoscopic group (26.7\%). ${ }^{30}$ Batra et al demonstrated a $22 \%$ major complication rate in endoscopic surgery, compared with $44 \%$ for open surgery. ${ }^{35}$
Open approaches theoretically may allow wider margins of tumor excision, and they may appear easier due to the wider approach, increased space for instruments and surgical maneuvers, and stereoscopic vision through an operating microscope. They also allow easier control of bleeding and CSF leakage. Endoscopic approaches are generally less destructive, avoiding osteotomies, and do not usually affect cosmesis. They allow enhanced visibility especially when using endoscopes with different angles of vision, and usually do not require tracheotomy or feeding tubes after surgery. However, endoscopy requires specialized and expensive equipment, and it lacks the depth of field perception of the operating microscope, although it is possible to appreciate depth of field by moving the endoscope toward and away from the region being observed in a dynamic fashion.

\section{Conclusion}

Open surgical approaches have long been considered the gold standard for treating lesions of the skull base, but recent advances in endoscopic techniques have increased the popularity of this method. Our series suggests that, in patients for whom open maxillotomy or endoscopic surgery are both feasible, the preference should be toward endoscopic surgery. In these patients, endoscopic surgery affords better visualization, potentially fewer complications, and is more acceptable to the patient. However, for midline pathology below the level of the hard palate, accessible via the oropharynx, we advocate that the standard transoral operation is a viable alternative to endoscopic surgery, with a lower infection and CSF leak rate than the endoscopic technique.

\section{Acknowledgments}

This work was performed at UCLH, which receives Biomedical Research Centre funding from the National Institute of Health Research. David Choi receives funding from the European Research Council.

\section{References}

1 Ammirati M, Bernardo A. Management of skull base chordoma. Crit Rev Neurosurg 1999;9(2):63-69

2 Crumley RL, Gutin PH. Surgical access for clivus chordoma. The University of California, San Francisco, experience. Arch Otolaryngol Head Neck Surg 1989;115(3):295-300

3 Hwang PY, Ho CL. Neuronavigation using an image-guided endoscopic transnasal-sphenoethmoidal approach to clival chordomas. Neurosurgery 2007;61(5, Suppl 2):212-217; discussion 217-218

4 Swearingen B, Joseph M, Cheney M, Ojemann RG. A modified transfacial approach to the clivus. Neurosurgery 1995;36(1): 101-104; discussion 104-105

5 Nakase H, Ohnishi H, Matsuyama T, Morimoto T, Sakaki T. Twostage skull base surgery for tumours extending to the sub- and epidural spaces. Acta Neurochir (Wien) 1998;140(9):891-898

6 Tuite G, Crockard HA. On the use of lateral surgical approaches to lesions at the craniocervical junction. Neuro-Orthopaedics 1995; 17(18):47-56 
7 Crockard HA, Cheeseman A, Steel T, et al. A multidisciplinary team approach to skull base chondrosarcomas. J Neurosurg 2001;95(2): 184-189

8 Crockard HA, Steel T, Plowman N, et al. A multidisciplinary team approach to skull base chordomas. J Neurosurg 2001;95(2): 175-183

9 Crockard HA, Johnston F. Development of transoral approaches to lesions of the skull base and craniocervical junction. Neurosurg $Q$ 1993;3(2):61-82

10 James D, Crockard HA. Surgical access to the base of skull and upper cervical spine by extended maxillotomy. Neurosurgery $1991 ; 29(3): 411-416$

11 Liu JK, Couldwell WT, Apfelbaum RI. Transoral approach and extended modifications for lesions of the ventral foramen magnum and craniovertebral junction. Skull Base 2008;18(3):151-166

12 Casey AT, Crockard HA, Stevens J. Vertical translocation. Part II. Outcomes after surgical treatment of rheumatoid cervical myelopathy. J Neurosurg 1997;87(6):863-869

13 Fraser JF, Nyquist GG, Moore N, Anand VK, Schwartz TH. Endoscopic endonasal minimal access approach to the clivus: case series and technical nuances. Neurosurgery 2010;67(3 Suppl Operative):ons150-ons158

14 Fraser JF, Nyquist GG, Moore N, Anand VK, Schwartz TH. Endoscopic endonasal transclival resection of chordomas: operative technique, clinical outcome, and review of the literature. J Neurosurg 2010;112(5):1061-1069

15 Stammberger H, Anderhuber W, Walch C, Papaefthymiou G. Possibilities and limitations of endoscopic management of nasal and paranasal sinus malignancies. Acta Otorhinolaryngol Belg 1999;53(3):199-205

16 Snyderman CH, Carrau RL, Prevedello DM, Gardner P, Kassam AB. Technologic innovations in neuroendoscopic surgery. Otolaryngol Clin North Am 2009;42(5):883-890, x

17 Snyderman CH, Pant H, Carrau RL, Prevedello D, Gardner P, Kassam $\mathrm{AB}$. What are the limits of endoscopic sinus surgery?: the expanded endonasal approach to the skull base Keio J Med 2009;58(3): 152-160

18 Stippler M, Gardner PA, Snyderman CH, Carrau RL, Prevedello DM, Kassam AB. Endoscopic endonasal approach for clival chordomas. Neurosurgery 2009;64(2):268-277; discussion 277-278

19 Choi D, Crockard HA. Transoral approaches to midline pathology of the ventral skull base. In: Bambakidis NC, Dickman CA, Spetzler $\mathrm{RF}$, Sonntag VK, eds. Surgery of the Craniocervical Junction. 2nd ed. New York, NY: Thieme; 2012

20 Kassam A, Snyderman CH, Mintz A, Gardner P, Carrau RL. Expanded endonasal approach: the rostrocaudal axis. Part II. Posterior clinoids to the foramen magnum. Neurosurg Focus 2005;19(1):E4
21 Kassam AB, Thomas A, Carrau RL, et al. Endoscopic reconstruction of the cranial base using a pedicled nasoseptal flap. Neurosurgery 2008;63(1, Suppl 1):ONS44-ONS52; discussion ONS52-ONS53

22 Zanation AM, Snyderman CH, Carrau RL, Kassam AB, Gardner PA, Prevedello DM. Minimally invasive endoscopic pericranial flap: a new method for endonasal skull base reconstruction. Laryngoscope 2009;119(1):13-18

23 Hadad G, Bassagasteguy L, Carrau RL, et al. A novel reconstructive technique after endoscopic expanded endonasal approaches: vascular pedicle nasoseptal flap. Laryngoscope 2006;116(10): $1882-1886$

24 Kassam A, Snyderman CH, Carrau RL, Gardner P, Mintz A. Endoneurosurgical hemostasis techniques: lessons learned from 400 cases. Neurosurg Focus 2005;19(1):E7

25 Tosun F, Carrau RL, Snyderman CH, Kassam A, Celin S, Schaitkin B. Endonasal endoscopic repair of cerebrospinal fluid leaks of the sphenoid sinus. Arch Otolaryngol Head Neck Surg 2003;129(5): 576-580

26 Kennedy DW. Functional endoscopic sinus surgery. Technique. Arch Otolaryngol 1985;111(10):643-649

27 Stammberger H, Posawetz W. Functional endoscopic sinus surgery. Concept, indications and results of the Messerklinger technique. Eur Arch Otorhinolaryngol 1990;247(2):63-76

28 Snyderman C, Kassam A, Carrau R, Mintz A, Gardner P, Prevedello DM. Acquisition of surgical skills for endonasal skull base surgery: a training program. Laryngoscope 2007;117(4):699-705

29 Carrabba G, Dehdashti AR, Gentili F. Surgery for clival lesions: open resection versus the expanded endoscopic endonasal approach. Neurosurg Focus 2008;25(6):E7

30 Casler JD, Doolittle AM, Mair EA. Endoscopic surgery of the anterior skull base. Laryngoscope 2005;115(1):16-24

31 Komotar RJ, Starke RM, Raper DM, Anand VK, Schwartz TH. Endoscopic skull base surgery: a comprehensive comparison with open transcranial approaches. Br J Neurosurg 2012;26(5): 637-648

32 Kassam AB, Prevedello DM, Carrau RL, et al. Endoscopic endonasal skull base surgery: analysis of complications in the authors' initial 800 patients. J Neurosurg 2011;114(6):1544-1568

33 Solares CA, Fakhri S, Batra PS, Lee J, Lanza DC. Transnasal endoscopic resection of lesions of the clivus: a preliminary report. Laryngoscope 2005;115(11):1917-1922

34 Choi D, Crockard HA. Evolution of transoral surgery: three decades of change in patients, pathologies, and indications. Neurosurgery 2013;73(2):296-304

35 Batra PS, Citardi MJ, Worley S, Lee J, Lanza DC. Resection of anterior skull base tumors: comparison of combined traditional and endoscopic techniques. Am J Rhinol 2005;19(5):521-528 